\title{
O comportamento das exportações brasileiras de produtos florestais e sua posição competitiva no mercado internacional no período de 1997 a 2011
}

\author{
Rosianne Pereira Da Silva ${ }^{1}$ \\ Gisalda Carvalho Filgueiras ${ }^{2}$ \\ Sérgio Luiz De Medeiros Rivero ${ }^{3}$ \\ Márcio Nazareno Da Silva ${ }^{4}$
}

\begin{abstract}
Resumo: O trabalho teve como objetivo central analisar o comportamento das exportações brasileiras de produtos florestais no período de 1997 a 2011, destacando-se os segmentos mais representativos a nível internacional: polpa de celulose, madeira serrada e painéis compensados. Discutem-se as mudanças estruturais e competitivas e os fatores que influenciaram as exportações brasileiras destes produtos através do modelo Constant-market-share - CMS que tomou como base teórica a Nova Teoria do Comércio Internacional. Os resultados permitem constatar que os ganhos de competitividade e de tamanho do mercado foram os fatores que mais contribuíram para a expansão das exportações brasileiras tanto da polpa de madeira, quanto para os painéis de madeira compensada.
\end{abstract}

Palavras-Chave: Competitividade, Constant-Market-Share, produtos florestais JEL: F12, Q23.

\section{The Behavior of Brazilian exports of forest products and their competitive position in the international market in the Period 1997 to 2011}

\footnotetext{
1 Mestre em Economia pela Universidade Federal do Pará - UFPA e Doutoranda no Programa de Doutorado em Ciências Agrárias da Universidade Federal Rural da Amazônia - UFRA. E-mail: rosiann@hotmail.com 2 Doutora em Ciências Agrárias pela Universidade Federal Rural da Amazônia. Professora na Universidade Federal do Pará. E-mail: gisalda.filgueiras@gmail.com

3 Doutor em Desenvolvimento Sustentável do Trópico Úmido pela Universidade Federal do Pará (2004). Professor da Universidade Federal do Pará e professor colaborador da Universidade Federal de Rondônia. E-mail: rivero@ufpr.br 4 Aluno de Especialização em Gestão Hídrica e Ambiental do Programa de Geociências da UFPA. E-mail:marciondasilva@hotmail.com
} 
Abstract: In this paper we analyze the behaviour of Brazilian exports of forest products from 1997 to 2011, highlighting the most representative segments of the industry: pulp, lumber and veneer. We discuss the structural and competitive changes and the factors influencing Brazilian exports of these products by using the constant-market-share-CMS approach, based on the framework of the new theory of international trade. As a main result we verified that the gains in competitiveness and market size were the factors that most contributed to the expansion of Brazilian exports of wood pulp, and of plywood panels.

Key-words: Competitiveness, Constant-market-share, forest products

JEL: F12, Q23.

\section{Introdução}

O comércio mundial de produtos florestais segundo a Food and Agriculture Organization of the United Nations - FAO (2012) abrange todos os produtos, madeireiros e não madeireiros, originários de matérias-primas exploradas de florestas naturais e plantadas e tem como países de maior tradição na exploração: Canadá, Alemanha, Estados Unidos da América - EUA, Suécia, Finlândia, Federação Russa, China, França, Áustria, Indonésia e Brasil. No entanto, apenas o Brasil e a Indonésia apresentam parte de suas produções provenientes de florestas tropicais (FAO, 2012).

A pressão mundial em atender as expectativas socioambientais de forma sustentável, faz aumentar a cada dia a demanda por produtos florestais certificados, sinalizando a tendência de elevação das áreas destinadas a florestas plantadas e dos números de certificações nestes países para os próximos anos.

A grande diversidade de segmentações e produtos, ao longo de toda a cadeia produtiva e sua significância socioeconômica, torna o setor florestal um dos mais importantes para a população mundial, pois contribui largamente para a geração de emprego e renda.

O Brasil possui a maior extensão de floresta tropical do planeta, o que equivale a 2/3 de seu território. Abrangendo, segundo a FAO (2012), 554 milhões de hectares. Deste total, 539 milhões são de florestas naturais e aproximadamente 6,5 milhões são provenientes de florestas plantadas, respondendo em 2011, por uma receita bruta de $\mathrm{R} \$ 53,9$ bilhões, $\mathrm{R} \$$ 7,6 bilhões de impostos arrecadados e geração de 4,7 milhões de empregos diretos e indiretos (ABRAF, 2012).

O País abriga a maior diversidade biológica e é, simultaneamente, o maior produtor e líder mundial em consumo de madeira tropical. Suas condições naturais e os recursos existentes oferecem-lhe uma condição privilegiada frente aos seus concorrentes internacionais. Contudo, apesar de possuir uma disponibilidade efetiva de 350 milhões de hectares de floresta natural e um potencial sustentável de 113 milhões de $\mathrm{m}^{3}$ por ano, a participação brasileira no comércio mundial de produtos florestais em 2011, segundo dados da FAO 
(2012), foi de apenas 4\%, tendo grande parte da sua produção formada por biomassa para uso energético, ou seja, lenha e carvão vegetal.

A elevação da demanda global por energia, e a necessidade mundial em atender as perspectivas ambientais de forma sustentável, que a cada dia se preocupa mais com os impactos negativos causados pela geração da energia não renovável e pelo consumo consciente, levaram à reestruturação da matriz energética de alguns países, que passaram a explorar mais intensamente outras fontes de energias, entre elas as renováveis, principalmente a partir do processo de queima da madeira.

O Brasil é o maior país da América Latina em extensão de floresta sustentável e a importância socioambiental deste setor para a sociedade brasileira pode ser mensurada pela avaliação de seus principais indicadores econômicos e sociais. Entretanto, o ano de 2011 foi de estagnação em termos de investimentos e expansão da área existente de floresta plantada, permanecendo, segundo dados da ABRAF (2012) em 6,5 milhões de ha. A grande volatilidade financeira internacional, a incerteza acerca dos rumos a serem tomados após a crise que se alastrou pelos EUA e Europa, além de alguns fatores internos como: as restrições à aquisição de terras por empresas brasileiras com maioria de capital estrangeiro e os longos prazos demandados pelos órgãos de fiscalização ambientais estaduais, foram fatores que contribuíram para esta estagnação.

O desenvolvimento da atividade florestal madeireira de forma sustentável, se apresenta como uma alternativa de substituição à exploração da energia baseada em combustíveis fósseis, evidenciando a importância da promoção de políticas de investimentos à expansão do setor, a fim de explorar sua potencialidade produtiva, principalmente às atividades voltadas à exportação. Neste sentido, o estudo teve por objetivo analisar o comportamento das exportações de alguns segmentos do setor florestal brasileiro (madeira em tora, madeira serrada, polpa de madeira, papel reciclado, papel cartão e painéis de madeira compensada) no período de 1997 a 2011. Destacando, devido a grande importância no comércio mundial a polpa de madeira e os painéis de madeira compensada, mostrando sua posição competitiva no mercado internacional, através do modelo Constant-market-share - CMS.

O estudo esta subdividido em cinco seções. Além desta introdução, a seção 2 apresenta a metodologia aplicada ao trabalho, a seção 3 aborda o panorama do mercado mundial e brasileiro de produtos florestais. Na seção 4 foram analisados os resultados da aplicação do modelo CMS e por fim, a seção 5 corrobora sobre as considerações finais.

\section{Metodologia}

Neste item serão apresentados o referencial teórico em que se embasou a pesquisa, as fontes consultadas e o modelo CMS. 


\subsection{Fonte de dados}

As informações sobre as variáveis da pesquisa, foram selecionados no banco de dados da FAO, do Instituto Brasileiro de Geografia e Estatística - IBGE, Fundação Getúlio Vargas - FGV e Ministério do Desenvolvimento, Indústria e Comércio Exterior - MDIC.

\subsection{Referencial Teórico}

O estudo teve como base a Nova Teoria do Comércio Internacional - NTCI, por fornecer inovações que refutam algumas premissas da teoria que a antecede (Teoria Neoclássica) incorporando as economias de escala, comércio intra-indústria e a competitividade. Dando assim, um formato mais realista da economia internacional.

Os princípios fundamentais da teoria neoclássica, ou teoria pura do comércio internacional, foram formulados por dois economistas suecos, Eli Heckscher, em 1919 e Bertil Ohlin, em 1933. Porém, o economista norte-americano Paul Samuelson (1948) foi quem deu o formato analítico e matemático, a esta abordagem. O modelo Heckscher e Ohlin (H-O), busca aperfeiçoar a teoria das vantagens comparativas das nações de David Ricardo (1982) - que já analisava os determinantes do comportamento do crescimento das exportações e a competitividade - iniciando por introduzir uma nova característica ao modelo, ou seja, a possibilidade de diferentes proporções de fatores entre os países. Procura explicar os ganhos do comércio internacional por meio de quatro teoremas fundamentais: $\mathrm{O}$ teorema Heckscher-Ohlin ( $\mathrm{H}-\mathrm{O})$, o teorema da Equalização dos Fatores, teorema Stolper - Samuelson (S-S) e teorema de Rybezynski.

O modelo H-O, conforme Krugman e Obstefeld (2001), postula que as vantagens comparativas são provenientes de níveis distintos de estoques relativos dos diferentes fatores produtivos, impactando diretamente os custos de produção desses diferentes bens, enquanto que o modelo ricardiano atribuiu a presença de vantagens comparativas a diferentes produtividades do trabalho entre os países. A abordagem moderna diferencia-se desta teoria, principalmente, por fazer distinção entre o comércio internacional e o comércio inter-regional e na identificação dos fatores que determinam a existência de vantagens comparativas, levando em conta não somente os diferenciais de produtividade do trabalho, como também os diferenciais de outros fatores produtivos, como o capital e recursos naturais por constituírem fatores que determinam a produtividade da mão de obra.

Por não refletir a realidade do comércio internacional, os pressupostos da Teoria Neoclássica se tornaram insuficientes para explicar os padrões do comércio internacional na presença de economias de escalas, pois não refletiam um cenário real para uma indústria. Não explicavam a elevação nos 
ganhos de comércio decorrente da elevação das importações e exportações de uma mesma indústria, pois ignoraram que na economia real grande parte do comércio internacional se dá entre parceiros comerciais relativamente semelhantes e no interior da indústria. Dessa forma, novas teorias surgem para explicar a parcela do comércio internacional que a teoria anterior não conseguia mais explicar, sendo denominadas então por NTCI.

Krugman (2001) e Linder (1961), na contramão do que afirmava a Teoria H-O, mostram que é possível o comércio entre países com estruturas de produção similares, denominando-o de comércio intra-indústria. Dois fatores básicos justificavam tal possibilidade: as economias de escala (defendida por Krugman $^{1}$ ) e a diversidade dos gostos dos consumidores (inserida por Linder ${ }^{2}$ ).

"Além destas duas teorias, a Teoria Ciclo-Produto de Raymond Vernon (1972) e as Teorias baseadas na Estrutura dos Mercados de vários autores, entre eles Krugman e Chamberlain formam as Novas Teorias do Comércio Internacional" (Luz, 2006 p.36). Esta teve como precursores Krugman (2001), Lancaster (1980) e Helpman (1981), e surge, para explicar essa nova característica das relações de troca entre os países: de diferenciação de produtos, das economias de escalas e da competição monopólica. Integram a velha e a nova teoria ao incorporar a diferenciação horizontal do produto e retornos crescentes de escala em um modelo, apresentando vantagens comparativas baseados em dotações de fatores.

Refutando as hipóteses neoclássicas de concorrência perfeita e retornos constantes de escala, Krugman (2001) considera as economias de escala como único fator determinante para o comércio intra-indústria, pois estas proporcionam às indústrias de um país vantagens em termos de custos (economia de custos) que lhes permitem exportar. Para Krugman (2001), tanto a variedade de bens, como a escala de produção nas indústrias onde existem economias de escala possuem como restrição o tamanho do mercado, que pode ser eliminada pelo comércio entre os países, aumentando seu tamanho através do comércio internacional. Cada nação deve se especializar na produção de uma variedade menor de bens e importar de outras, ou seja, os bens que ela não possui vantagem e que não produz.

A NTCI também busca explicar o papel das empresas multinacionais no comércio internacional, pois uma parcela significativa do comércio mundial ocorre entre subsidiárias dessas empresas, estas trocas são denominadas essencialmente comércio intra-indústria. Esse comércio, segundo Krugman e Obstfeld (2001), produz ganhos extras no comércio internacional, superiores aos ganhos obtidos com as vantagens comparativas.

1 Paul Krugman em sua NTCI assume como premissas básicas: as economias de escala (Teoria dos Ganhos de Escala), a concorrência imperfeita e o comércio intra-indústria.

2 Staffan Burastam Linder (1961) formulou uma teoria alternativa que era consistente com os resultados encontrado por Leontief em seu estudo sobre as exportações norte-americanas no pós-Segunda Guerra Mundial. 


\subsection{O Modelo Constant-Market-Share (CMS)}

O método CMS permite a analisar a competitividade das exportações dos principais segmentos do setor florestal (polpa de madeira e painéis de madeira compensada), identificando as causas do seu crescimento, comparando desempenho do mercado exportador em relação ao mercado importador (Leamer; Stern, 1970).

Para aplicação do modelo CMS é necessário definir alguns padrões que servirão de base para que seja analisado o desempenho e estrutura das exportações brasileiras de polpa de madeira e de painéis compensados no período estudado. Para isso, foi utilizada a base de dados disponibilizada pela FAO (2011).

A aplicação do modelo é realizada entre pontos discretos no tempo, desta forma, há necessidade de se fixarem períodos de análise. Neste trabalho foi considerado o período de 1997 a 2010, decomposto em dois subperíodos, cada um correspondendo à média de sete anos, como forma de minimizar o efeito de um ano até o pico, selecionados de forma a representar alguns momentos importantes para a economia brasileira.

Desta forma tem-se:

a) O Primeiro subperíodo (1997 a 2003), representando a fase de estabilização da economia brasileira e seus impactos sobre o setor exportador e o início da alavancagem das exportações brasileiras de produtos florestais;

b) O Segundo subperíodo (2004 a 2010), que representa a expansão das exportações brasileiras; e relativo aos anos mais recentes de consolidação das exportações dos produtos florestais.

O método atribui o crescimento favorável/desfavorável das exportações ao setor exportador, tanto na estrutura de exportações do país, quanto na competitividade. De modo que, mantida a parcela de exportação do país, a variação percebida é devida à competitividade (Carvalho, 2004). Sendo que a variação do comportamento das exportações é decomposto, de modo a se ter a seguinte identidade:

$$
\begin{aligned}
V_{. .}^{\prime}-V & \equiv \sum_{i} \sum_{j} r_{i j} V_{i j}+\sum_{i} \sum_{j}\left(V_{i j}^{\prime}-V_{i j}-r_{i j} V_{i j}\right) \\
& \equiv r V+\sum_{i}\left(r_{i}-r\right) V_{i}+\sum_{i} \sum_{j}\left(r_{i j}-r_{i}\right) V_{i j}+\sum_{i} \sum_{j}\left(V_{i j}^{\prime}-V_{i j}-r_{i j} V_{i j}\right)
\end{aligned}
$$

(a)

(b) (c)

$(d)$ 
Esta identidade permite a decomposição da taxa de crescimento das exportações do país A, em quatro efeitos:

(a) crescimento do comércio mundial, que é o aumento observado se as exportações do país analisado tiverem crescido à mesma taxa do comércio mundial;

(b) composição da pauta: mudanças na estrutura da pauta com concentração em mercadorias com crescimento de demanda mais ou menos acelerado. Neste estudo este efeito é nulo por estudarmos apenas os produtos florestais;

(c) destino das exportações: mudanças decorrentes das exportações de mercadorias para mercados de crescimento mais ou menos dinâmicos;

(d) competitividade: calculado como um efeito residual resultante da diferença entre o crescimento das exportações e o crescimento efetivo das exportações.

Ao se considerar a diferenciação das exportações por destino e por tipo de mercadoria, chega-se ao modelo CMS para um tipo particular de mercadoria e uma região particular de destino, conforme especificado na equação acima.

\section{Panorama do mercado mundial de produtos florestais}

A nova ordem econômica global que se delineou nos últimos anos posicionou alguns países emergentes entre os maiores no ranking do desenvolvimento mundial. O Brasil, apesar do baixo crescimento apresentado em 2011 (2,7\%), passou a ocupar o $6^{0}$ lugar nesta classificação. Para o país, estas transformações esboçou internamente um cenário positivo em diversos setores da economia, abrindo novas perspectivas de investimentos, inclusive para o setor florestal. Contudo, o ano de 2011 foi marcado pela estagnação nos investimentos deste setor, evidenciando certa preocupação por parte dos empresários do ramo, quanto aos rumos tomados pela crise financeira que afetou fortemente os EUA e a Europa, assim como a incerteza sobre os pontos a serem aprovados pelo novo Código Florestal Brasileiro.

Nos últimos anos, alguns segmentos do setor florestal brasileiro foram marcados pela estagnação ou crescimento pouco expressivo, tanto a nível mundial, quanto a nível nacional. Fato que pode ser confirmado ao se analisar a produção mundial de madeira em tora, que entre os anos de 1997 a 2011 não apresentou crescimento. Em 1997, a oferta mundial foi de 3,3 bilhões de $\mathrm{m}^{3}$ e em 2011 esta produção foi de 3,4 bilhões de $\mathrm{m}^{3}$, um crescimento de apenas 3,2\% em relação ao ano de 1997 (tabela 1). Índia, EUA, China, Brasil, Rússia e Canadá foram os maiores produtores mundiais em 2011, juntos foram responsáveis por 49,5\% de toda a produção mundial, equivalente a 1,6 bilhões de $\mathrm{m}^{3}$. O Brasil foi o $4^{\mathrm{O}}$ no ranking dos maiores produtores, participando com $7,9 \%$ da oferta global, cerca de 271,5 milhões de $\mathrm{m}^{3}$. 
SILVA, R.P.; FILGUEIRAS, G. C.; RIVERO, S.L.M.; SILVA, M.N. O comportamento das exportações....

TABELA 1 - EVOLUÇÃO E CRESCIMENTO DA PRODUÇÃO MUNDIAL DE MADEIRA EM TORA $\left(\mathrm{M}^{3}\right)$

\begin{tabular}{|c|c|c|c|c|c|c|}
\hline \multirow[b]{2}{*}{ Países } & \multicolumn{2}{|l|}{1997} & \multicolumn{2}{|l|}{2011} & \multirow{2}{*}{$\begin{array}{c}\text { Variação } \\
(\%) \\
\text { 1997/2011 }\end{array}$} & \multirow{2}{*}{$\begin{array}{c}\text { TGC * } \\
1997^{-} \\
2011\end{array}$} \\
\hline & Mil m³ & $\begin{array}{l}\text { Partici- } \\
\text { pação \% }\end{array}$ & Mil m³ & $\begin{array}{c}\text { Partici- } \\
\text { pação } \\
\%\end{array}$ & & \\
\hline Índia & 296.469 .016 & 8,91 & 332.498 .878 & 9,68 & 12,2 & $-14,2 \%$ \\
\hline EUA & 464.231 .008 & 13,95 & 324.432 .676 & 9,44 & $(-30,1)$ & $-2,6$ \\
\hline China & 347.631 .712 & 10,45 & 291.250 .552 & 8,48 & $(-16,2)$ & $-1,3 \%$ \\
\hline Brasil & 213.479 .519 & 6,42 & 271.500 .740 & 7,90 & 27,2 & $1,73 \%$ \\
\hline Rússia & 134.664 .000 & 4,05 & 197.000.000 & 5,73 & 46,3 & $2,40 \%$ \\
\hline Canadá & 191.058 .000 & 5,74 & 145.066 .000 & 4,22 & $(-24,1)$ & $-2,6$ \\
\hline Outros & 1.679 .666 .437 & 50,48 & 1.873 .695 .767 & 54,54 & 11,5 & $1 \%$ \\
\hline Mundo & $3 \cdot 327.199 .692$ & 100,00 & 3.435 .444 .613 & 100,00 & 3,1 & $0,22 \% * *$ \\
\hline
\end{tabular}

Fonte: FAO (2012)

*TGC = Taxa Geométrica de Crescimento (\% ao ano)

** Não significante estatisticamente

A produção mundial de madeira em tora destinada a industrialização também não apresentou crescimento no período de 1997 a 2011, já a produção brasileira cresceu a uma taxa média de $3 \%$ a.a. Os EUA, Rússia, Canadá, Brasil e China foram os maiores produtores, respondendo em 2011, por $52 \%$ da produção mundial. Em 1997, a produção mundial de madeira em tora foi de 1,53 bilhões de $\mathrm{m}^{3}$ (Tabela 2). Em 2005, esta produção já somava 1,7 bilhões $\left(\mathrm{m}^{3}\right)$, maior volume já produzido pelo mundo em toda a série. Este crescimento foi puxado pelo Brasil, Rússia e EUA, que expandiram sua produção em 10,7\%, 5,7\% e $1,3 \%$ respectivamente.

Os anos subsequentes foram de queda, mas foi no ano de 2009, diante da incerteza em que se encontrava a economia global após a crise financeira norte-americana, que esta produção apresentou maior declínio, 9,7\% em relação ao ano de 2008 (1,4 bilhões $\mathrm{m}^{3}$ ). Em 2011, a oferta mundial deste segmento voltou a elevar-se somando um total de 1,55 bilhões de $\mathrm{m}^{3}$ produzidos.

No Brasil, segundo dados da FAO (2012), a produção de madeira em tora destinada a industrialização em 2010 totalizou 128,4 milhões $\mathrm{de}^{3}$, sendo que deste total, 115,7 milhões de $\mathrm{m}^{3}$ foram proveniente de produção sustentada de floresta plantada e 12,7 milhões de $\mathrm{m}^{3}$ de origem extrativista, gerando um valor bruto da produção (VBP) de R \$ 9,3 milhões (IBGE, 2012). 
TABELA 2 - PRODUÇÃO MUNDIAL DE MADEIRA EM TORA DESTINADA À INDUSTRIALIZAÇAO: 1997-2011 (BILHÕES M³)

\begin{tabular}{cccccccccc}
\hline Anos & EUA & Russia & Canadá & Brasil & China & Resto do mundo & Mundo \\
\hline 1997 & 416 & 88 & 186 & 85 & 107 & 652 & 1.534 \\
1998 & 424 & 77 & 174 & 84 & 107 & 642 & 1.507 \\
1999 & 423 & 95 & 191 & 100 & 100 & 649 & 1.558 \\
2000 & 421 & 106 & 199 & 103 & 96 & 696 & 1.621 \\
2001 & 403 & 118 & 183 & 90 & 94 & 653 & 1.541 \\
2002 & 405 & 119 & 195 & 96 & 93 & 668 & 1.576 \\
2003 & 406 & 127 & 177 & 120 & 95 & 697 & 1.621 \\
2004 & 418 & 131 & 205 & 107 & 95 & 721 & 1.676 \\
2005 & 424 & 138 & 200 & 118 & 95 & 754 & 1.729 \\
2006 & 412 & 145 & 181 & 119 & 95 & 726 & 1.677 \\
2007 & 379 & 162 & 161 & 122 & 91 & 779 & 1.694 \\
2008 & 337 & 137 & 136 & 115 & 101 & 748 & 1.574 \\
2009 & 292 & 113 & 113 & 122 & 101 & 690 & 1.431 \\
2010 & 284 & 136 & 139 & 128 & 102 & 745 & 1.534 \\
2011 & 284 & 153 & 142 & 128 & 102 & 747 & 1.557 \\
\hline
\end{tabular}

Fonte: Food Agricultural Organization (FAO, 2012)

A produção de toras de plantios florestais - incluindo carvão vegetal (equivalente em madeira em tora), lenha, madeira em tora para energia, celulose, serraria e laminação oriundas somente da silvicultura- totalizou 179 milhões de $\mathrm{m}^{3}$ em 2011 (ABRAF, 2012). Desse total, 67,3\% (120,7 milhões de $\mathrm{m}^{3}$ ) foram direcionados ao uso industrial, 28,8\% (51,7 milhões de $\mathrm{m}^{3}$ ) à produção de lenha e 3,9\% (6,9 milhões de m³) à produção de carvão.

A Tabela 3 mostra a evolução da produção em $\mathrm{m}^{3}$, do VBP (R\$), quantidades e valores exportados da madeira em tora brasileira destinada à industrialização. Observa-se, que ao longo do período em análise, a renda bruta recebida pelo produtor cresceu a uma taxa média de 5,1\% a.a., o mesmo não foi observado pelos valores recebidos com a comercialização externa deste produto, que apresentou TGC negativa de 24,3\% a.a. Ressalta-se, que a implementação do marco regulatório da política ambiental na Amazônia e a substituição da madeira por produtos concorrentes ${ }^{3}$ contribuíram para a redução da extração da madeira e comercialização ilegal, que em quase todo o período, apresentou queda. O ano de 2010 revelou uma redução absoluta de 52\%, relativo ao ano de 1997. A substituição da madeira tropical por madeira proveniente de florestas sustentáveis provocou um aumento superior a 100\% na produção advinda da madeira silvicultura.

3 Forro de PVC, esquadrias de alumínio substituindo as madeira, as formas de metal, amplamente utilizada pela indústria de construção civil vertical em substituição ás de madeira e o MDF em substituição aos móveis produzidos com madeira tropical. 
Em quase todo o período, o comércio externo brasileiro deste segmento apresentou superávit, no entanto, suas exportações nos últimos anos, mostraram quedas consecutivas (Tabela 3). Em 2011, o saldo da balança comercial brasileira fechou em US $\$ 2.805$, uma redução de 30,3\% (cerca de 24 milhões de $\mathrm{m}^{3}$ ) em relação ao ano de 2009. A crise econômica financeira global, o aumento da demanda interna, aliado a estagnação da área destinada à floresta plantada pelas empresas, foram fatores que contribuíram para esta retração.

TABELA 3 - PRODUÇÃO (M³), VBP (R\$ MIL) E BALANÇA COMERCIAL DA MADEIRA EM TORA BRASILEIRA (US\$ MIL): 1997-2011

\begin{tabular}{r|r|r|r|r|r|r}
\hline Anos & $\begin{array}{c}\text { Produção } \\
\text { Milhões } \\
\mathrm{m}^{3}\end{array}$ & $\begin{array}{c}\text { VBP } \\
\text { R\$ Mil }\end{array}$ & $\begin{array}{c}\text { Quant. } \\
\text { Exportada } \\
\text { Milhões } \\
\mathrm{m}^{3}\end{array}$ & $\begin{array}{c}\text { Exportação } \\
\text { US\$ Mil }\end{array}$ & $\begin{array}{c}\text { Importação } \\
\text { US\$ Mil }\end{array}$ & $\begin{array}{c}\text { Saldo } \\
\text { US\$ } \\
\text { Mil }\end{array}$ \\
\hline 1997 & 84.684 & 1.802 .052 & 791.800 & 50.328 & 1.394 & 48.933 \\
1998 & 83.764 & 2.203 .019 & 935.300 & 62.150 & 1.427 & 60.723 \\
1999 & 100.395 & 2.006 .485 & 442.000 & 30.094 & 1.360 & 28.735 \\
2000 & 102.994 & 2.157 .652 & 753.600 & 45.122 & 1.854 & 43.269 \\
2001 & 89.827 & 2.505 .419 & 563.079 & 22.544 & 3.795 & 18.749 \\
2002 & 96.438 & 3.213 .617 & 950.611 & 28.952 & 1.229 & 27.723 \\
2003 & 120.361 & 4.907 .115 & 123.305 & 4.664 & 1.048 & 3.616 \\
2004 & 106.618 & 5.224 .988 & 100.021 & 6.028 & 2.397 & 3.631 \\
2005 & 117.987 & 6.603 .885 & 25.004 & 2.053 & 1.720 & 333 \\
2006 & 118.754 & 7.125 .039 & 7.225 & 880 & 3.051 & -2170 \\
2007 & 121.520 & 7.281 .829 & 18.553 & 4.198 & 558 & 3.641 \\
2008 & 115.390 & 7.246 .212 & 27.473 & 6.747 & 1.439 & 5.308 \\
2009 & 122.160 & 8.653 .607 & 5.610 & 1.192 & 2.712 & -1520 \\
2010 & 128.400 & 9.387 .733 & 24.000 & 5.202 & 1.178 & 4.024 \\
2011 & 128.400 & 9.387 .733 & 24.000 & 5.090 & 2.285 & 2.805 \\
\hline
\end{tabular}

Fonte: FAO (2012)

Nota $^{1}$ : VBP=Valores deflacionados pelo IGP-DI, base dez 2011;

Nota2 ${ }^{2}$ Exportações, importações e saldo: Valores deflacionados pelo IPC EUA, base dez 2011

A madeira serrada também não apresentou crescimento entre os anos de 1997 a 20114. Os EUA, Canadá, China, Federação Russa, Brasil e Alemanha foram os maiores produtores mundiais e juntos responderam com 54,7\% da oferta mundial em 2011, que foi de 400,5 milhões $\mathrm{m}^{3}$, muito superior à demanda global, que neste mesmo ano foi de 115,6 milhões $\mathrm{m}^{3}$. Em 2011, o 4 Com TGC de 0,32\% a.a, sem significância estatística. 
segmento elevou em 2,6\% sua produção, em relação ao ano de 2010, contudo, não conseguiu sustentar o bom desempenho referente à 2009, quando teve um crescimento de 7,1\%. Em comparativo ao ano de 2006, cuja produção foi de 447 milhões $\mathrm{m}^{3}$, a oferta global em 2011 apresentou retração de 10,4\%.

\section{GRÁFICO 1 - PRODUÇÃO MUNDIAL DE MADEIRA SERRADA: 1997 - 2011(MILHÕES M3)}

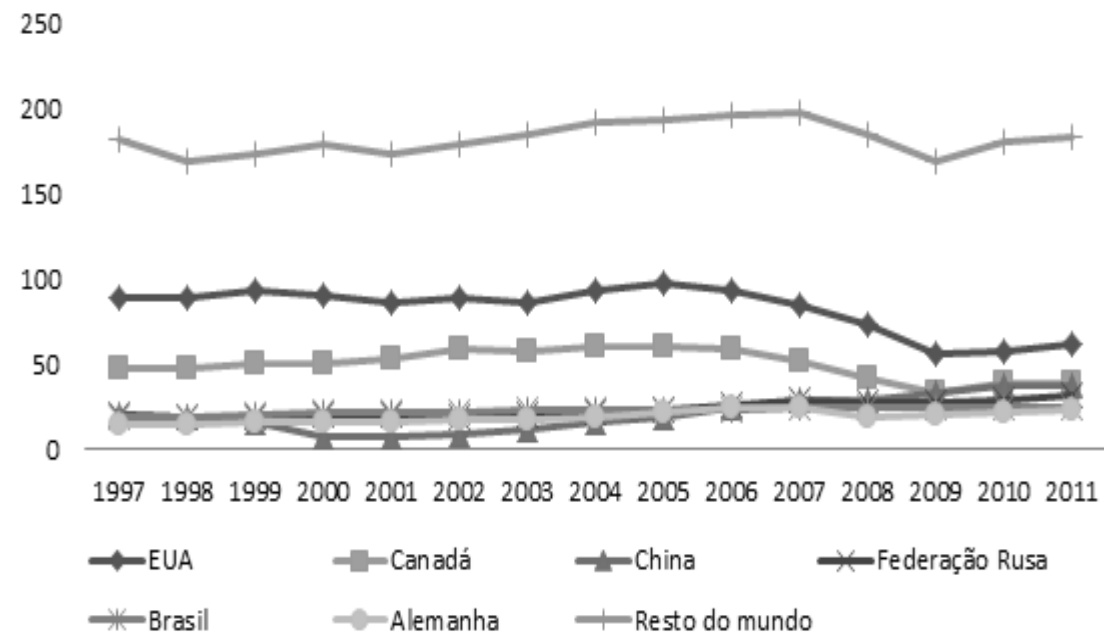

Fonte: Food Agricultural Organization (FAO, 2012)

Nota: Elaborado pelos autores

O Brasil apresentou crescimento médio de $2 \%$ a.a. neste mesmo período. Em 2005, se posicionou como quarto no ranking da produção mundial de madeira serrada, em 2011, perdeu uma posição, caindo para o quinto lugar, atingindo cerca de 25,8 milhões de $\mathrm{m}^{3}$, participando com cerca de $6,3 \%$ da produção global, enquanto que os EUA, principal produtor mundial, teve participação de 15,4 \%, cerca de 61,6 milhões de $\mathrm{m}^{3}$ (Gráfico 1).

No que tange ao mercado mundial, as exportações brasileiras de madeira serrada, segundo dados da FAO (2012), apresentaram queda nos últimos cinco anos (Gráfico 2). A baixa quantidade exportada em relação à produzida pode ser explicada pelo aumento da demanda interna, principalmente o setor da construção civil que absorve quase que completamente toda a oferta nacional.

O Gráfico 2 mostra ainda, que no ano de 1997 a quantidade exportada gerou uma renda de US\$ 542 milhões, cerca de 1,6 milhões de $\mathrm{m}^{3}$, equivalente a $8,2 \%$ da produção nacional neste mesmo ano. Nos anos seguintes os volumes exportados apresentaram aumentos sucessivos (com exceção do ano de 2003) 
até o ano de 2004, quando atingiu o maior quantitativo já exportado (3,7 milhões $\mathrm{m}^{3}$ ) gerando uma renda de US\$1,03 bilhão. Após 2005 as exportações voltaram a cair, fechando o ano de 2011 com apenas 1,4 milhões de $\mathrm{m}^{3}$, gerando receita de US\$ 502 milhões dólares, segundo dados da FAO (2012).

\section{GRÁFICO 2 QUANTIDADE (M³) E VALOR (MILHÕES US\$) DAS EX- PORTAÇÕES BRASILEIRAS DE MADEIRA SERRADA: 1997-2011}

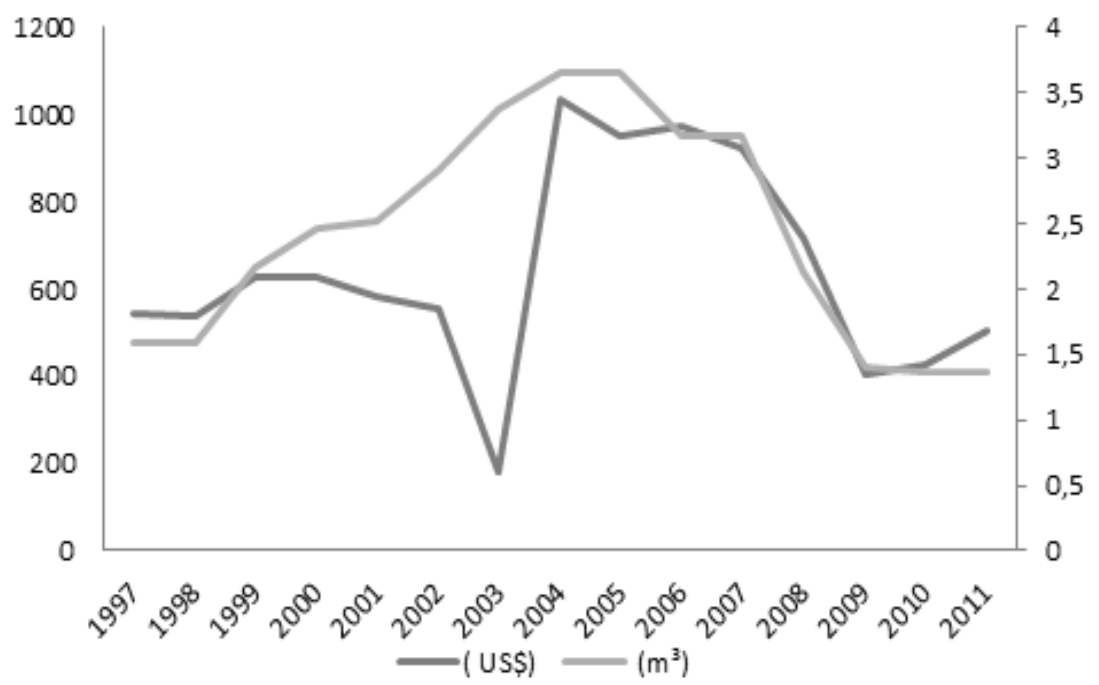

Fonte: Food Agricultural Organization (FAO, 2012)

Nota1: Valores deflacionados pelo IPC-EUA, base: dezembro 2011.

A produção mundial de polpa de madeira exibiu um crescimento pífio, desenvolvendo-se muito abaixo dos demais segmentos da floresta, com taxa média de crescimento de $0,45 \%$ a.a, no período em análise. A a expansão da produção global deste insumo exibe dois picos bastantes significativos, nos anos 2000, quando apresenta variação positiva de $5,1 \%$, respondendo por 172 milhões de toneladas - recuando no ano seguinte em 4,5\%, devido ao cenário de desaceleração da economia mundial - e no ano de 2010, depois da grande retração sofrida nos anos de 2008 (-1,9\%) e 2009 (-9,5\%), em razão da crise financeira mundial culminada nos EUA, quando exibe um crescimento de 6,3\% em relação ao ano anterior. Em 2011 a oferta global de polpa de madeira foi cerca de 180 milhões de toneladas, uma elevação de $1 \%$ em relação ao ano anterior.

EUA, Canadá e Brasil foram os maiores produtores mundiais de polpa de madeira em 2011, respondendo juntos por 48,8 \% de toda oferta mundial 
(Gráfico 3), equivalente a 84,1 milhões de toneladas.

\section{GRÁFICO 3: PRODUÇÃO MUNDIAL DE POLPA DE MADEIRA EM 2011 (TONELADAS)}

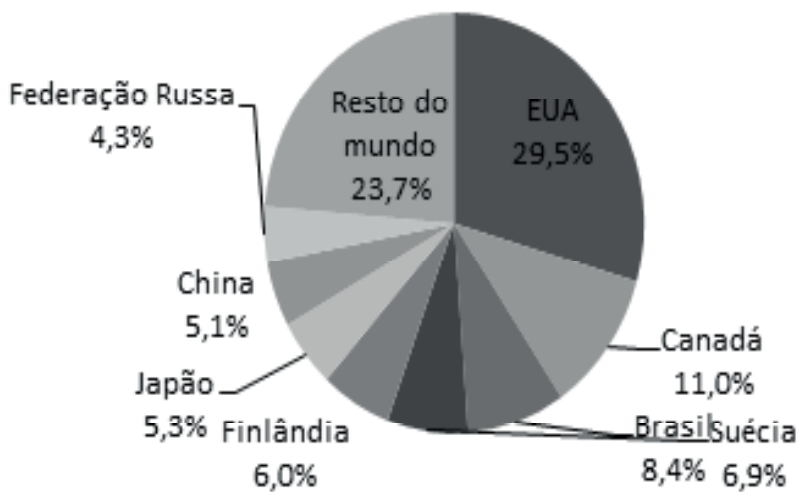

Fonte: Food Agricultural Organization (FAO, 2012)

A produção brasileira apresentou crescimento médio de 6,6\% a.a. entre os anos de 1997 a 2011, diferente dos EUA e Canadá, que no mesmo período não obtiveram crescimento, apresentando taxas médias negativas, 1,14\% e 2,4\%, respectivamente. Em 1997, o Brasil participou com 4\% da produção global deste segmento, cerca de 6.421 mil de toneladas. No ano seguinte, esta produção já somava 12.850 mil de toneladas, participando em $7,2 \%$ da oferta total mundial, representando, em termos absolutos, mais de $100 \%$ em relação ao primeiro ano analisado. Este crescimento deve-se em grande parte a expansão da demanda mundial, no entanto, grande parte desta produção advém de madeira de floresta plantada, que justamente a partir dos anos 90, passa novamente a tomar impulso em razão de um desenvolvimento racional e sustentável, buscando a adequação a nova legislação ambiental que exige e dita as novas regras para o uso consciente dos recursos e as novas formas de manejo da floresta.

O Brasil, terceiro maior produtor mundial em 2011, respondeu com 8,4\% da oferta global de celulose, cerca de 14,4 milhões de toneladas, segundo dados da FAO (2012). Altos investimentos na indústria e o bom desempenho econômico do Brasil foram fatores que contribuíram para a boa atuação neste segmento nos últimos anos.

No que se refere às exportações, Canadá, Brasil e EUA foram os países que mais exportaram polpa de madeira em 2011, seguidos do Chile, Suécia e Indonésia. Ao se observar a evolução das exportações no período, pode-se notar que em 1997 (Tabela 4), as exportações mundiais somaram 34,9 milhões de toneladas 
gerando receita de US\$22,3 milhões. O Brasil, no mesmo ano exportou 2.503 mil toneladas, totalizando US\$1,4 milhões. A crise financeira global iniciada em 2008 provocou ligeira queda nas exportações mundiais em 2009 (2,4\%), no entanto, o Brasil expandiu em 19,2\% suas exportações, cerca de $8.586 \mathrm{~m}^{3}$, respondendo pela receita de US\$3, 45 milhões, cerca de 14\% da receita das exportações mundiais.

Em 2011, o comércio mundial deste insumo retomou o crescimento e as exportações brasileiras elevaram-se para 8.886 mil toneladas, cerca de $16,5 \%$ de toda a polpa de madeira comercializada pelo mundo, totalizando US\$ 4.9 milhões, 14,3\% das receitas obtida com a comercialização mundial.

A demanda mundial de papel reciclado cresceu em média 8,5\% a.a, entre os anos de 1997 a 2011, tendo a China (49,4\%), Alemanha (7,2\%), Holanda (5,2\%), Índia $(4,5 \%)$ e Indonésia $(4,1 \%)$ como maiores demandantes. Juntas, foram responsáveis pelo consumo de 70,4\% de todo o papel reciclado comercializado pelo mundo em 2011, cerca de 40 milhões de toneladas.

A oferta mundial deste segmento cresceu em média 4,5\% a.a, bem a baixo do crescimento médio de sua demanda no mesmo período, concentrando-se, nos últimos anos, entre os EUA, Japão, China e Alemanha. Sendo que em 2011, a China figurou como maior produtora, com 47,4 milhões de toneladas - 3,3 milhões de toneladas a mais do que a produzida em 2010 -, seguida pelos EUA (46,8 milhões) e Japão (21,8 milhões).

O Brasil que desde 2009, ocupa o $10^{\circ}$ lugar no ranking dos maiores produtores deste segmento, participou, em 2011, com 2\% da produção mundial, produziu cerca de 4 milhões de toneladas. Deste total, apenas 5.0oo toneladas foram exportadas, gerando receita de US\$1.459 mil, segundo dados da FAO (2012).

O Gráfico 6 mostra a evolução da produção de papel reciclado e papel cartão no período de 1997 a 2011. Observa-se que no mercado de papel e papel cartão (Gráfico 4), o Brasil ocupou, em 2011, o $11^{\circ}$ lugar no ranking dos produtores mundiais, alcançando uma produção de 9,9 milhões de toneladas, equivalente a 2,43\% da produção mundial, segundo dados da FAO (2012), pouco se elevando $(0,4 \%)$ em relação ao ano de 2010, quando a produção brasileira foi de 9,8 milhões de toneladas, correspondendo a 2,45\% da produção mundial de celulose.

Os principais produtores mundiais neste segmento em 2011 foram a China, EUA e Japão, responsáveis por 51\% de toda a oferta mundial, cerca de 207 milhões de toneladas. 
TABELA 4 -EVOLUÇÃO DAS EXPORTAÇÕES MUNDIAIS E BRASILEIRAS DE POLPA DE MADEIRA E PARTICIPAÇÃO (\%) DAS EXPORTAÇÕES BRASILEIRAS NAS EXPORTAÇÕES MUNDIAIS: 1997-2011

\begin{tabular}{c|c|c|c|c|c|c}
\hline \multirow{2}{*}{ Anos } & \multicolumn{2}{|c|}{\begin{tabular}{c} 
Exportações Mundiais \\
\cline { 2 - 7 }
\end{tabular}} & $\begin{array}{c}\text { Exportações Brasi- } \\
\text { lierias }\end{array}$ & \multicolumn{2}{c}{$\begin{array}{c}\text { Participação (\%) } \\
\text { Brasil/Mundo }\end{array}$} \\
\cline { 2 - 7 } & $\begin{array}{c}\text { Quant. } \\
\text { Milhões }\end{array}$ & $\begin{array}{c}\text { Valor } \\
\text { US\$ } \\
\text { Milhões }\end{array}$ & $\begin{array}{c}\text { Quant. } \\
\text { Milhões }\end{array}$ & $\begin{array}{c}\text { Valor } \\
\text { US\$ } \\
\text { Milhões }\end{array}$ & $\begin{array}{c}\text { Quantidade } \\
(\%)\end{array}$ & $\begin{array}{c}\text { Valor } \\
(\%)\end{array}$ \\
\hline 1997 & 34.945 & 22,26 & 2.503 & 1,43 & 7,2 & 6,4 \\
1998 & 35.004 & 20,69 & 2.803 & 1,45 & 8,0 & 7,0 \\
1999 & 37.096 & 21,54 & 3.109 & 1,68 & 8,4 & 7,8 \\
2000 & 38.315 & 27,70 & 3.010 & 2,09 & 7,9 & 7,6 \\
2001 & 38.705 & 20,72 & 3.349 & 1,59 & 8,7 & 7,7 \\
2002 & 40.812 & 19,89 & 3.416 & 1,45 & 8,4 & 7,3 \\
2003 & 42.084 & 22,09 & 4.566 & 2,13 & 10,8 & 9,7 \\
2004 & 43.295 & 24,01 & 4.987 & 2,05 & 11,5 & 8,5 \\
2005 & 43.163 & 23,82 & 5.545 & 2,34 & 12,8 & 9,8 \\
2006 & 46.370 & 26,73 & 6.238 & 2,77 & 13,5 & 10,3 \\
2007 & 48.059 & 30,98 & 6.571 & 3,27 & 13,7 & 10,5 \\
2008 & 48.571 & 33,16 & 7.203 & 4,08 & 14,8 & 12,3 \\
2009 & 47.423 & 24,62 & 8.586 & 3,45 & 18,1 & 14,0 \\
2010 & 49.885 & 34,96 & 8.793 & 4,90 & 17,6 & 14,0 \\
2011 & 53.733 & 37,15 & 8.886 & 4,99 & 16,5 & 13,4 \\
\hline
\end{tabular}

Fonte: FAO

Nota: Valores deflacionados pelo IPC-EUA, base dez 2011=100.

As importações de papel reciclado, em 2011 apresentaram retração de 2,3\% em relação ao ano de 2010, com consumo de 105,6 milhões de toneladas, cerca de 2,5 milhões de toneladas a menos, em comparação ao ano anterior. Tendo a Alemanha, EUA, Reino Unido, França, Itália, México e China como maiores consumidores, cerca de $43 \%$ de todo o consumo mundial. 
GRÁFICO 4 - EVOLUÇÃO DA PRODUÇÃO BRASILEIRA DE PAPEL RECICLADO, PAPEL E PAPEL CARTÃO (TONELADAS): 1997 - 2011

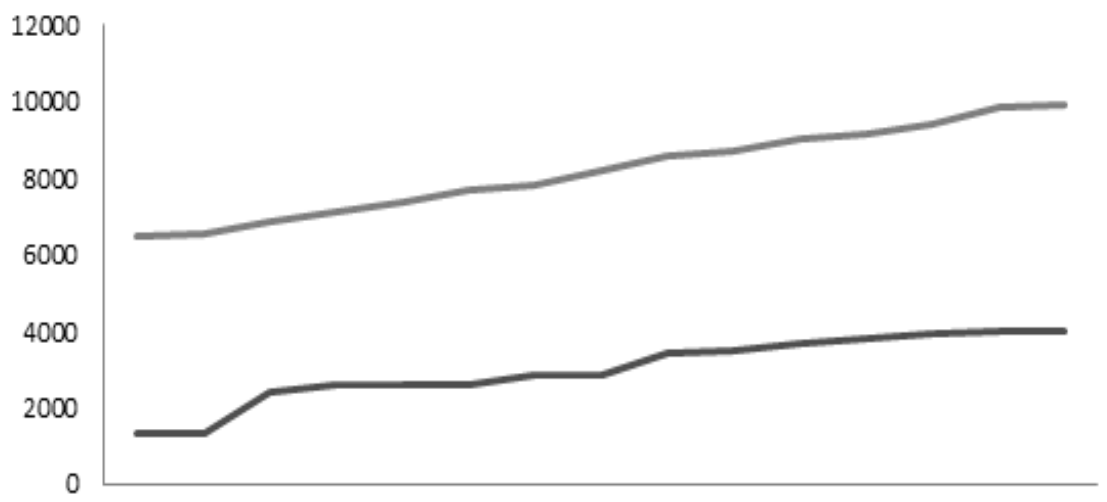

199719981999200020012002200320042005200620072008200920102011

- Papele papel cartão Papel reciclado

Fonte: Food Agricultural Organization (FAO, 2012)

Nota: Elaborado pelos autores

O consumo mundial de produtos florestais apresentou um crescimento médio de 2,3\% a.a entre o período analisado, gerando em 2011 um montante de US 608 bilhões, segundo a FAO. Em comparação a 1997, primeiro ano da série em estudo, quando a demanda mundial gerou uma renda de US\$489,5 bilhões de dólares, em 2011 a demanda mundial de produtos florestais cresceu significativamente, apresentando uma variação acumulada de $24 \%$.

Em 2011, esta demanda foi bastante pulverizada, a China (6,6\%), EUA (3,2\%), Alemanha (3,2 \%) e Japão (2\%) foram os maiores importadores, demandando juntos 16\% de todo total, segundo dados da FAO (2012). O Brasil teve como maiores importadores em 2010, China (10,2\%), os EUA (9,6\%), Holanda (5,6\%), Itália (4,71\%) e Bélgica (3,19\%), que juntos consumiram 33\% do total comercializado internacionalmente pelo Brasil.

As exportações mundiais de produtos florestais totalizaram, em 2011, US\$ 241,4 milhões, 58\% foram exportados pelo EUA (10,8\%), Canadá (9,4\%), Alemanha (9\%), Suécia (7,19\%), Finlândia (5,8\%), China (6,7\%), Federação Russa (4\%), França (3,4\%) e Brasil (3,3\%). Este exportou US $\$ 8$ bilhões em 2011, apresentando elevação de 2,2\% em relação a 2010, quando exportou US\$ 7,9 bilhões.

No período estudado, as exportações brasileiras de produtos florestais cresceram a uma taxa média de 6,5\% a.a, segundo dados da FAO (2012). Entretanto, 
para o primeiro subperíodo (1997 a 2003), o país não apresentou crescimento ${ }^{5}$. Este passa a ser manifestado a partir do ano de 2004 até 2011, quando as exportações brasileiras apresentaram um crescimento médio de 4,6\% a.a. De fato, a partir de 2004 a média das exportações brasileiras no segundo subperíodo (US\$ 6,8 bilhões) é quase que o dobro da média do primeiro subperíodo, que foi de 3,9 bilhões. Apesar da pequena retração no comércio internacional de produtos florestais em 2011, o saldo da balança comercial de alguns segmentos deste setor permaneceu positivo.

\section{Resultados e Discussões}

A análise da competitividade de um determinado produto ou segmento pode ser considerada pela sua participação e desempenho em seus mercados destino, ou mercados alvo. Para avaliar a competitividade do setor florestal brasileiro foram escolhidos, devido a grande representatividade no setor, três segmentos: a polpa de celulose, madeira serrada e painéis compensados.

Aplicação do modelo CMS permitiu uma análise mais precisa destes segmentos no mercado internacional, mostrando através da desagregação dos efeitos (tamanho de mercado, distribuição e competitividade), a influência que cada um teve nas exportações brasileiras nos subperíodos 1997-2003 e 2004-2010.

\subsection{Polpa de Celulose}

Para o primeiro subperíodo (1997-2003), os dez países selecionados consumiram juntos em média US $\$ 665,3$ milhões em polpa de madeira, comercializados pelo Brasil, cerca de $41 \%$. A Bélgica, Japão e a Itália foram os principais importadores, com percentual médio de $16 \%, 10,2 \%$ e 5,7\%\%, respectivamente. Neste subperíodo as exportações brasileiras deste segmento não apresentaram crescimento, isto pode ser devido à vários fatores, entre eles: i) a falta de incentivos ao setor florestal brasileiro, que desde 1987 suprimiu o Fundo de incentivo Setorial, ii) à ausência de fontes de financiamentos e de uma política direcionada às especificidades do setor florestal que priorizasse ações de manejo sustentados e iii) a falta de modernização do setor, tornando-o menos competitivo no mercado internacional.

Somente a partir do ano 2000, com a implantação do Programa Nacional de Floresta, pelo Ministério do Meio Ambiente - que tinha por objetivo promover e expandir o desenvolvimento do setor de base florestal de forma sustentável, a fim de alavancar a demanda, tanto interna quanto externa, conciliando a exploração com a proteção do meio ambiente, foi que a indústria nacional de celulose ganhou novo impulso. 
Todos os principais países importadores de polpa de madeira brasileira, expandiram consideravelmente suas importações no segundo subperíodo. Finlândia, Bélgica, Itália, China, Japão e Polônia foram os que mais demandaram, com destaque para a Finlândia e a Bélgica que no primeiro subperíodo importaram 3,8\% e $16 \%$, neste demandaram $56 \%$ e $32 \%$, respectivamente. Vale ressaltar, que os EUA, desde 1997 eram os maiores consumidores da polpa de madeira brasileira, em 2010 demandaram US\$ 68,3 milhões, ficando em $11^{\mathrm{O}}$ no ranking dos maiores importadores deste segmento.

A Tabela 5 ilustra a origem das mudanças nas exportações brasileiras de polpa de madeira, comprovando que a participação média do Brasil no total comercializado pelo mundo se elevou de 7\% para 10\% entre os anos de 2004 a 2010.

TABELA 5-ORIGEM DAS MUDANÇÃS NA MÉDIA ANUAL DAS EXPORTAÇÕES BRASILEIRAS DE POLPA DE MADEIRA NOS SUBPERÍODOS 1997/2003 E 2004/2010 (em US\$ 1000 FOB)

\begin{tabular}{|c|c|c|c|c|}
\hline \multirow{2}{*}{ TOTAL MUNDIAL } & \multicolumn{4}{|c|}{ Fluxo de comércio (efetivo) } \\
\hline & 1997/2003 & & $2004 / 2010$ & \\
\hline Importação mundial & 22.968 .481 & & 29.835 .289 & \\
\hline Exportação do Brasil & 1.622 .708 & (A) & 3.137 .799 & (B) \\
\hline Market-share (\%) & $7,06 \%$ & & $10,52 \%$ & \\
\hline $\begin{array}{l}\text { EXPORTAÇÕES POTENCIAIS } \\
\text { DO BRASIL }\end{array}$ & Variação & & Exportações & \\
\hline $\begin{array}{l}\text { Mantendo market-share } \\
\text { mundial em 1997/2003 }\end{array}$ & 485.135 & (C) & $2.107 .843,0$ & (D) \\
\hline $\begin{array}{l}\text { Mantendo market-share em cada } \\
\text { país em 1997/2003 }\end{array}$ & 347.154 & $(\mathrm{E})$ & $1.969 .861,6$ & $(\mathrm{~F})$ \\
\hline $\begin{array}{l}\text { Market-share potencial para } \\
\text { 2004/2010 - média mundial (\%) }\end{array}$ & & & $7,06 \%$ & \\
\hline $\begin{array}{l}\text { Market-share potencial para } \\
\text { 2004/2010 - média países (\%) }\end{array}$ & & & $6,60 \%$ & \\
\hline NATUREZA DAS VARIAÇÕES & Efeitos & & Proporção & \\
\hline Variação efetiva (B - A) & $1.515 .091,3$ & & $100,00 \%$ & \\
\hline Tamanho de mercado (D - A) & 485.135 & & $32,02 \%$ & \\
\hline Distribuição de mercado (F - D) & -137.981 & & $-9,11 \%$ & \\
\hline Competitividade (B- F) & $1.167 \cdot 937$ & & $77,09 \%$ & \\
\hline Soma dos efeitos & & & $100,00 \%$ & \\
\hline
\end{tabular}

Fonte: Dados da pesquisa.

O crescimento do consumo mundial, provavelmente, influenciou o efeito positivo do tamanho do mercado, que foi de $32 \%$. Isso demonstra que os 
exportadores brasileiros estão expandindo e diversificando seus mercados, principalmente para a Ásia e União Europeia, com destaque para a China, Finlândia e Polônia, que em 2010 elevaram, consideravelmente, suas importações. Vale considerar que os EUA e a União Europeia sempre foram os maiores parceiros comerciais do Brasil neste segmento.

A contribuição do efeito competitividade (77,1\%), mas que compensou o efeito negativo da distribuição do mercado de exportação (9,1\%) e, possivelmente, foi devido a ampliação da capacidade instalada das indústrias, que vem buscando melhorar, cada vez, mais a estrutura de seu parque industrial e adequar seus produtos à níveis exigidos internacionalmente.

Ressalta-se, que em 2011, o Brasil, foi o terceiro maior produtor mundial de polpa de madeira, segundo dados da FAO (2012), com uma produção de 14,4 milhões de toneladas, cerca de 8,4\% do total produzido mundialmente. Além de ser o segundo maior exportador mundial deste segmento, participando com 16,5\% das exportações mundiais, perdendo somente para o Canadá (18\%), e gerando uma renda de cerca US $\$ 5$ milhões, um superávit de US $\$ 4,6$ milhões na balança comercial de celulose.

\subsection{Painéis de Madeira Compensada ${ }^{6}$}

O consumo mundial de painéis compensados vem crescendo consideravelmente nos últimos dez anos. Apesar de ter apresentado, no ano de 2009, uma forte queda em virtude da crise econômica financeira global, $28 \%$ em relação ao ano de 2008, nos anos de 2010 e 2011 voltou a expandir-se apresentando crescimento de $19 \%$ e $4,17 \%$, respectivamente, equivalente a US $\$ 10,9$ e US\$ 11 milhões. Os maiores demandantes mundiais de painéis compensados em 2011, foram o Japão (15\%), EUA (14\%), Alemanha (7\%), Reino Unido (6\%) e China (6\%), que juntos consumiram US $\$ 5,1$ milhões, cerca de $46 \%$, de toda a demanda mundial de madeira compensada, segundo dados da FAO (2012).

O Brasil que no ano de 2001 participou com 6,6\% de toda a oferta global, em 2011, foi responsável por 3\% desta produção, uma retração de mais de 50\% em relação àquele ano, cerca de 2,2 milhões de $\mathrm{m}^{3}$, segundo dados da FAO (2012). Em relação à participação brasileira no mercado internacional, entre os anos de 1997 a 2011, as exportações de painéis compensados apresentaram crescimento médio de $6,7 \%$ a.a. Sendo que em 1997, representavam 4,5\% do total comercializados mundialmente (US\$ 264.255), crescendo consideravelmente ao longo do período. Em 2011, a participação brasileira foi de 5\%, cerca de US\$ 418.259.

A análise para primeiro subperíodo mostra, que os dez países selecionados importaram juntos cerca de $71 \%$ do total de painéis compensados comercializados pelo Brasil no mercado internacional. Os maiores importadores foram

6 Madeira compensada nomenclatura 1640 (FAO). 
Argentina, Jamaica e Reino Unido, com participação percentual média de $51,23 \%, 27,7 \%$ e $17,5 \%$, respectivamente. No geral, todos os países expandiram suas participações, com exceção da França que reduziu suas importações médias de para 3,1\%, no segundo subperíodo. Com destaque para a Jamaica que elevou para 48,5\% suas importações.

A Tabela 6 mostra que o market-share da madeira compensada brasileira se elevou de 4,5\% para 6,8\% no segundo subperíodo. As fontes de crescimentos calculadas evidenciam que, houve uma variação efetiva positiva de US\$ 336.390 para o segundo subperíodo, em relação ao primeiro. Os efeitos competitividade (51,3\%) e tamanho de mercado (34,2\%) contribuíram, conjuntamente, para a expansão das exportações brasileiras de madeira compensada no período em análise. Os resultados para o efeito distribuição de mercado $(14 \%, 5 \%)$, indica que o país precisa diversificar mais o mercado de forma a expandir mais suas exportações.

TABELA 6 - ORIGEM DAS MUDANÇAS NA MÉDIA ANUAL DAS EXPORTAÇÕES BRASI LEIRAS DE MADEIRA COMPENSADA, NOS SUBPERÍODOS DE 1997/2003 E 2004/2010 (em US\$ 1000 FOB)

\begin{tabular}{|c|c|c|c|}
\hline \multirow{2}{*}{ TOTAL MUNDIAL } & \multicolumn{3}{|c|}{ Fluxo de comércio (efetivo) } \\
\hline & $1997 / 2003$ & & $2004 / 2010$ \\
\hline Importação mundial & 9.373 .868 & & 11.698 .267 \\
\hline Exportação do Brasil & 463.863 & (A) & 800.253 (B) \\
\hline Market-share (\%) & $4,95 \%$ & & $6,84 \%$ \\
\hline $\begin{array}{l}\text { EXPORTAÇÕES POTENCIAIS DO } \\
\text { BRASIL }\end{array}$ & Variação & & Exportações \\
\hline $\begin{array}{l}\text { Mantendo market-share mundial } \\
\text { em 1997/2003 }\end{array}$ & 115.022 & (C) & $578.885 \quad(\mathrm{D})$ \\
\hline $\begin{array}{l}\text { Mantendo market-share em cada } \\
\text { país em 1997/2003 }\end{array}$ & 163.677 & (E) & $627.541 \quad(F)$ \\
\hline $\begin{array}{l}\text { Market-share potencial para } \\
\text { 2004/2010 - média mundial (\%) }\end{array}$ & & & $4,95 \%$ \\
\hline $\begin{array}{l}\text { Market-share potencial para } \\
\text { 2004/2010 - média países (\%) }\end{array}$ & & & $5,36 \%$ \\
\hline NATUREZA DAS VARIAÇÕES & Efeitos & & Proporção \\
\hline Variação efetiva (B - A) & 336.390 & & $100,00 \%$ \\
\hline Tamanho de mercado (D - A) & 115.022 & & $34,19 \%$ \\
\hline Distribuição de mercado (F - D) & 48.655 & & $14,46 \%$ \\
\hline Competitividade (B - F) & 172.713 & & $51,34 \%$ \\
\hline Soma dos efeitos & & & $100,00 \%$ \\
\hline
\end{tabular}

Fonte: Dados da pesquisa. 


\section{Considerações finais}

Atualmente, as empresas buscam cada vez mais elevar ou manter suas participações no mercado internacional. Para isso, a necessidade de se estabelecer estratégias competitivas para participar da nova economia globalizada fez com que muitas firmas desenvolvessem a habilidade de prospectar com maior eficiência o ambiente em que atua no mercado, tornando necessário um melhor conhecimento da organização e do funcionamento dos sistemas agroindustriais (Batalha, 2001; Zylbersztajn e Neves, 2000).

No setor florestal, não é diferente, conhecer profundamente todos os elos das cadeias produtivas de base, buscando sempre a eficiência de cada segmento industrial, a fim de suprir as exigência do mercado destino e tornar-se competitivo internacionalmente, é fundamental para o crescimento da produção e expansão das exportações.

Neste sentido, o estudo buscou mostrar a importância do setor florestal brasileiro analisado o comportamento da produção e exportação de alguns segmentos, como: madeira em tora, polpa de madeira, madeira serrada, papel reciclado, papel e papel cartão e painéis compensados. Destacando, por possuírem grande representatividade no mercado mundial, a polpa de madeira e painéis compensados, a fim de avaliar quais efeitos influenciaram o comportamento de suas exportações e sua posição competitiva no mercado internacional. Assim, o modelo Constant-Market-Share foi aplicado, desagregando sua variação em dois subperíodos (1997-2003 e 2004-2010) e em três efeitos distintos (tamanho do mercado, distribuição e competitividade).

Os resultados apresentados permitem constatar que o segundo subperíodo foi o de maior dinamismo para as exportações brasileiras de celulose e painéis de madeira compensada, pois ambas elevaram suas participações no mercado internacional. Os efeitos competitividade e tamanho do mercado atuaram conjuntamente para a expansão das exportações tanto da polpa de madeira, quanto dos painéis de compensados, sendo que o efeito competitividade em ambos os segmentos tiveram elevados percentuais médios que foi de $77 \%$ e $51 \%$, respectivamente.

Desta forma, pode-se considerar que estes segmentos apresentam um desempenho competitivo satisfatório no comércio mundial, pois elevaram seu market-share de um período para outro. A diversificação, o tamanho do mercado e a adequação das indústrias de base florestal aos padrões de qualidade exigidos internacionalmente, que o país vem assumindo nos últimos anos e que lhe permitiram ganhos de escala, foram fatores relevantes para o aumento das exportações brasileiras deste setor.

Para a NTCI, os ganhos do comércio seriam resultantes da economia de escala, que possibilitam maior produção a custos mais baixos e maior competitividade. Alguns segmentos do setor florestal brasileiro, após inúmeras transformações ocorridas nas últimas décadas, conseguiram alcançar escala 
e produtividade para responder ao aumento e determinações da demanda externa, como é o caso da indústria de celulose, que segundo o Instituto Poyry Internacional, é a terceira no ranking de competitividade internacional de custos de produção.

O crescimento da demanda mundial por produtos florestais brasileiros, exigiu que o setor se modernizasse, tornando-se mais competitivo, se ajustando aos padrões exigidos mundialmente. Neste sentido, as economias de escala e o conceito de competitividade nacional, que engloba a produtividade, explicam porque estes dois segmentos brasileiros (polpa de madeira e os painéis compensados) elevaram sua participação no mercado internacional no período analisado.

\section{Referências Bibliográficas}

Abraf - Associação Brasileira de Plantadores de Floresta Plantada. "Anuário Estatístico da ABRAF 2012." URL [on-line]: http://www.abraflor.org.br/estatisticas/ ABRAF12. Acesso em 21 de janeiro de 2012.

Batalha, M. O. (2001) “Gestão agroindustrial: grupo de Estudos e Pesquisas Agroindustriais/Coord.” 2.ed. São Paulo. Atlas.

Carvalho, F. M. A. (2004) Método "Constant Market Share” (CMS). In: SANTOS, ML. de; VIEIRA, W. da C. (Ed.). "Métodos Quantitativos em Economia”. Viçosa: $U F V . p .225-241$.

FAO - Food And Agriculture Organization Of United Nations. URL [on-line]: <http:// www.faostat.fao.org >. Acesso em 22 de maio de 2012.

FAO - Food And Agriculture Organization Of United Nations. "Anuário estatístico 2012." URL [on-line]: <http://www.fao.org >. Acesso em 25 de maio de 2012.

Helpman, E. (1981), "International Trade in the Presence of Product Differentiation, Economies of Scale, and Monopolistic Competition: A Chamberlin-Heckscher-Ohlin Approach," Journal of International Economics, 11, 305-34O.

IBGE - Instituto Brasileiro de Geografia e Estatística. <www.ibge.gov.br>. Acesso em 25 de maio de 2012.

Krugman, P. R.; Obstfeld, M. (2001). “Economia Internacional: Teoria e Política”. São Paulo. $5^{a}$ Edição. Ed. Makron Books.

Lancaster, K. (1980) “Intra-industry trade under perfect monopolistic competition", Journal ofInternational Economics 1O, 151-175.

Leamer, E. E.; Stern, R. M (1970). “Quantitative international economics”. Boston, Massachustts: Allyn and Bacon, Ch 7. P. 171-183.

Linder, S. B. (1961). "Um ensaio sobre o comércio e transformação”. Estocolmo: Almgvist \& Wicksell.

Luz, R. T. (2006). “Relações Econômicas Internacionais: Teoria e Questões”. Rio de Janeiro. Elsevier.

Ohlin, B. (1991) “The Theory of Trade”. In: HECKSCHER, E.F. e OHLIN. B. Heckscher-Ohlin Trade Theor. Cambridge. MA: The MIT Press. 
Ricardo, D. (1982). "Princípios de Economia Política e Tributação”. São Paulo: Abril Cultural.

Richardson J. D. (1971).“Constant-market-shares analysis of export growth”. Journal of International Economics, v. 1, p. 227-239.

Smith, A. (1983) "A riqueza das nações: investigação sobre sua natureza e suas causas”. São Paulo: Abril Cultural.

Samuelson, P. A. (1948). "Economics: As introductory Analysis". Massachusetts Institute of Tecnology, Cambridge, MA. New York: McGraw-Hill.

Stern. R. M. (1967). “Foreign trade and economic grow in Italy”. New York, Frederic A. Praeger, New York.

Vernon, R. (1972) “Manager in the International Economics.” 2nd Ed. New Jersey: Prentice-Hall.

Zylbersztajn, D.; Neves, M. F. "Economia e gestão dos negócios agroalimentares.” São Paulo: Pioneira, 2000.

Recebido em: 27 de setembro de 2012 Aceito em: 26 de fevereiro de 2013 